the star through the middle of the ring or bar. This supposition, however, is shown to be erroneous. For stars of a less magnitude than $5^{\circ} 5$ there is always a detention in the apparent time of emersion, which increases with the faintness of the stars observed. The cause of the error, therefore, is physiological, and due to the occulting micrometers employed. The law regulating it having been found, the necessary corrections have been applied to the measures, thus rendering the work of greater use.

The memoir represents the work of a business man over a period of twenty years, and with an instrument having an aperture of $3 \frac{1}{4}$ inches. It contains much of interest, and will doubtless be appreciated as an important contribution to the knowledge of the stars in a cluster which is certainly one of the grandest of telescopic objects.

\section{ON THE VEGETATION OF TIBET.}

I N the May number of the Fournal de Botanique MM. Bureau and Franchet describe a number of new plants from the collections recently brought home by M. Bonvalot and Prince Henry of Orleans, and give a general summary of their character, of which the following is an abstract :-

The collection was made almost entirely in a narrow band of territory reaching from Lhassa eastward near the 30 th parallel of north latitude by way of Batang and Sitang to Tatsienlow, in the province of Szechwan, in West China, from which place their route was deflected at a right angle to Yunnan.

Considered in its general aspect, the flora of this region, as shown in the collection, is marked by the stunted form of the shrubs and dwarf character of the herbaceous vegetation. Of the forest trees, Coniferæ and others, no specimens were brought. It is characteristically a vegetation of high peaks, where drought and strong winds are the main climatic features. The Papaveraceæ are represented especially by dwarf, largeflowered kinds of Meconopsis. The greater number of the species of Corydalis are not more than two or three inches high. The Cruciferæ, such as Parrya ciliaris, in the same way are dwarf and large-flowered. Silene caspitosa may be compared with the most dwarf states of $S$. acaulis of our own high mountains. The honeysuckle of Tibet constitutes only a small bush about a foot high, with intertangled branches. But it is especially in the Rhododendrons and Primulas that this dwarf character is remarkable. All the Rhododendrons and Primulas found between Lhassa and Sitang-R. principis, $R$. primulceflorum, R. nigropunctatum, Primula leptopoda, $P$. diantha, and $P$. Henrici may be ranged amongst the dwarfest types of the genera to which they belong. It is the same with Incurvillea. The Tibetan species belong to a group found also in Kansu and Central Yunnan, with stem almost obliterated and corolla very large.

Passing eastward in Szechwan the flora puts on a different character. The leaves become larger, the number of flowers to each plant increases. There are many Rosaceæ, Orchids, and species of Pedicularis ; amongst the Compositæ the genus Senecio is particularly well represented, and there are several Everlastings that approach the Edelweiss of the Swiss Alps.

The flora of this eastern part of Tibet and western region of Szechwan has a strong affinity both with that of the Sikkim Himalaya and that of Central Yunnan. Meconopsis Henrici represents the Himalayan $M$. simplicifolia, Hook, et Thoms. Astragalus litargensis, A. acaulis, Benth., Rubus xanthocarpus, R. sikkimensis; Brachyactis chinensis, B. menthodora; Gnaphalizum corymbosum answers to $G$. nubigenum; Androsace bisulca to $A$. microphylla; and there are many other similar parallels between the plants of Tibet and Sikkim, and in the same many parallels may be found between the new species found by our travellers in Tibet and those gathered by Delavay in Yunnan.

\section{SOCIETIES AND ACADEMIES. LONDON.}

Royal Society, June 18.- "An Apparatus for testing the Sensitiveness of Safety-lamps." By Frank Clowes, D.Sc. Lond., Professor of Chemistry, University College, Nottingham. Communicated by Prof. Armstrong, F.R.S.

The following apparatus has been devised to render easy the NO. I I 33, VOL. 44$]$ process of testing the sensitiveness of different forms of safetylamps when used for detecting firedamp. To enable satisfactory tests to be made in the laboratory, it was necessary to insure (r) the easy and rapid production of mixtures of firedamp and air in known proportions; (2) to insure economy of the artificially prepared methane, which represented firedamp; and (3) to examine the flame of the lamp under conditions as satisfactory as those existing in the mine.

A wooden cubical box of about Ioo litres capacity was constructed so as to be as nearly gas-tight as possible. It was then made absolutely gas-tight by painting it over with melted paraffin wax, which was afterwards caused to penetrate more perfectly by passing an ordinary hot flat-iron over the surface.

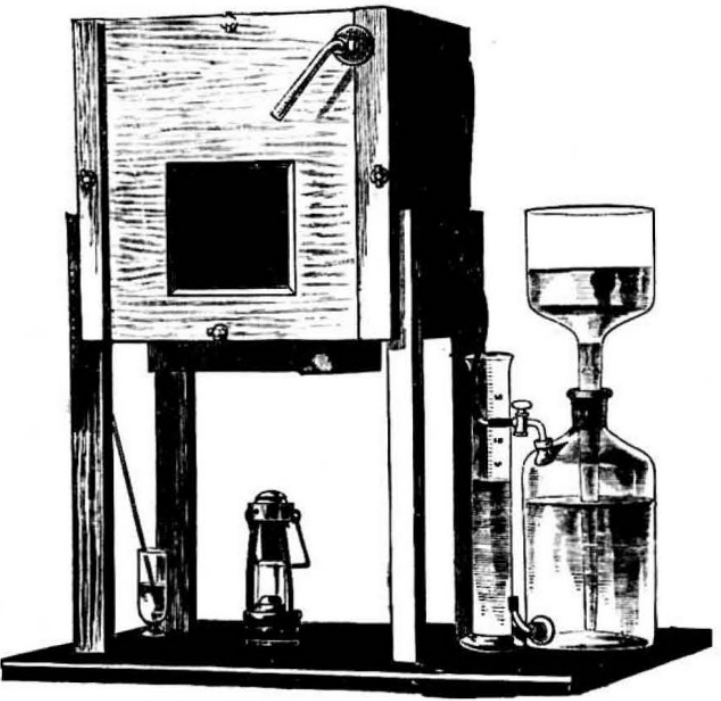

Fig. x.

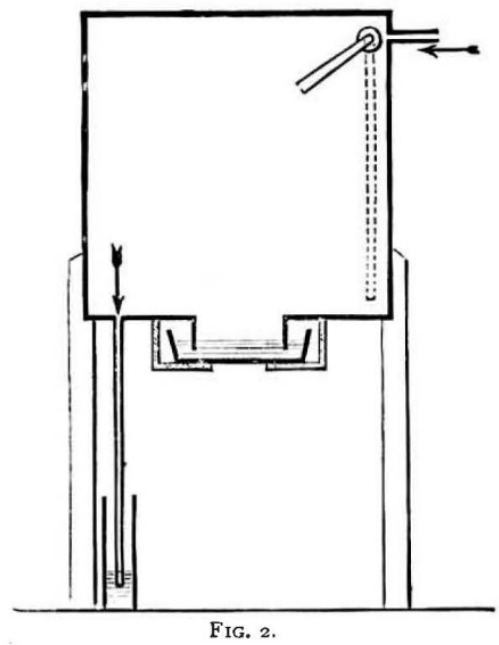

This testing chamber was furnished with a small inlet tube at the top, and with a similar outlet tube below. It had a plateglass window in front for observing the lamp in the interior, and a flanged opening below for introducing the safety-lamp. This opening was closed by a water-seal consisting of a small zinc tray supported by buttons, and containing about 2 inches depth of water, into which the flange dipped. A mixer was arranged, which consisted of a light flat board, nearly equal in dimensions to the section of the chamber, and suspended by an axis from the upper corner of the chamber. The mixer was moved rapidly backwards and forwards from the side to the top of the interior of the chamber, by grasping a handle projecting through the front of the chamber.

When a mixture of air with a certain definite precentage of 
firedamp was required, the methane, prepared and purified by ordinary chemical methods, was introduced into the chamber in the requisite quantity by the top inlet. It displaced an equal volume of air, which escaped through the lower outlet, the exit end of which was sealed by being immersed just beneath a water surface. A vigorous use of the mixer secured a uniform mixture of gas and air throughout the interior of the chamber in the course of a few seconds. The lamp was then introduced into the chamber, and placed in position behind the glass window. The simplicity of arrangement of the water-seal rendered the necessary opening of the chamber very brief, and the introduction and removal of the lamp many times in succession was not found to produce any appreciable effect upon the composition of the atmosphere inside the chamber. The appearance and dimensions of the "cap" over the flame were noted as soon as the cap underwent no further change. A lamp was left burning in the chamber for a considerable length of time, and its indications underwent no change, owing to the large capacity of the chamber and the very limited amount of air required to support the combustion of the small flame always used in gastesting. The whole interior of the chamber and mixer were painted dead-black, so as to render visible pale and small caps against a black ground.

The methane was introduced from an ordinary gas-holder. A volume of water, equal to that of the methane to be displaced, was poured into the top of the gas-holder. The gas-tap of the holder was then momentarily opened, so as to produce equilibrium of pressure between the methane and the atmosphere. The gas-tap having then been placed in connection with the upper inlet of the chamber, the water-tap was opened, and the measured volume of water was allowed to flow down and drive the methane into the chamber. As soon as bubbles of air ceased to appear through the water at the outlet, the chamber was closed; the mixer was then vigorously worked for a few seconds, and the mixture of gas and air was ready for the introduction of the lamp. Before introducing the methane for a fresh mixture, the atmosphere of the chamber was replaced by fresh air by removing the water-tray from beneath the opening at the bottom of the chamber, and blowing in a powerful stream of air from a bellows to the top of the chamber.

The chamber was supported on legs, which were arranged so as to place it at a convenient height for observations through the window, and also for the introduction and removal of the safetylamp.

The observations were usually made in a darkened room, but the flame-caps were easily seen in a lighted room, provided direct light falling on the eye or chamber was avoided.

The capacity of the chamber was 95,220 c.c. ; accordingiy, the following volumes of methane were introduced: for $\frac{1}{2}$ per cent. mixture 476 c.c., for I per cent. 952 c.c., for 2 per cent. 1904 c.c., for 3 per cent. 2856 c.c., for 4 per cent. 3808 c.c., and for 5 per cent. 4760 c.c. It will be seen that a series of tests, in which the above-mentioned percentage mixtures were employed, involves an expenditure of only 15 litres of methane, a quantity far smaller than that required by any other method of testing as yet described.

Of many forms of safety-lamp tested in the above apparatus, the one which most satisfactorily fulfilled the two purposes of efficient illumination and delicacy in gas-testing was Ashworth's improved Hepplewhite-Gray lamp. This lamp is of special construction, burns benzoline from a sponge reservoir, and its flame is surrounded with a glass cylinder, which is ground rough at the hinder part; this latter device prevents the numerous reflected images of the flame, and the generally diffused reflections which are seen from a smooth glass surface, and which render the observation of a small pale flame-cap very difficult, if not impossible.

The wick of this lamp, when at a normal height, furnishes a flame of great illuminating power. When lowered by a fine screw adjustment the flame becomes blue and non-luminous, and does not interfere therefore with the easy observation of pale cap. The following heights of flame-cap were observed, which fully bear out the unusual sensitiveness of this flame. With 0.5 per cent. of methane $7 \mathrm{~mm}$. ; with I per cent. Io $\mathrm{mm}$. ; with 2 per cent. $14 \mathrm{~mm}$. ; with 3 per cent. $20 \mathrm{~mm}$.; with 4 per cent. $25 \mathrm{~mm}$. ; and with 5 per cent. $30 \mathrm{~mm}$. The cap, which with the lower proportions was somewhat ill-defined, became remarkably sharp and definite when 3 per cent. and up wards of methane was present. But even the lowest percentage gave a cap easily seen by an inexperienced observer.
It appears from the above record of tests that the problem of producing a lamp which shall serve both for efficient illuminating and for delicate gas-testing purposes has been solved. The solution is in some nieasure due to the substitution of benzoline for oil, since the flame of an oil-lamp cannot be altogether deprived of its yellow luminous tip, without serious risk of total extinction; and this faint luminosity is sufficient to prevent pale caps from being seen.

From further experiments made in the above testing-chamber with flames produced by alcohol and by hydrogen, it was found to be true in practice, as might be inferred from theory, that, if the flame was pale and practically non-luminous, the size and definition of the flame-cap was augmented by increasing either the size or the temperature of the flame. It is quite possible by attending to these conditions to obtain a flame which, although it is very sensitive for low percentages of gas, becomes unsuitable for the measurement of any proportion of gas exceeding 3 per cent. This must, for the general purposes of the miner, be looked upon as a defect ; but it is not a fault of the lamp already referred to. It is of interest to note that with the Pieler spiritlamp a flame-cap an inch in height was seen in air containing only 0.5 per cent. of methane.

Physical Society, June 26. - Prof. W. E. Ayrton, F.R.S., President, in the chair.-The following communications were made :- The construction of non-inductive resistances, by Prof. W. E. Ayrton, F.R.S., and Mr. T. Mather. In making some transformer tests about three years ago, the authors had occasion to consider the construction of electric conductors the impedances of which should be practically equal to their resistances. This condition could only be fulfilled by making the inductance small in comparison with the resistance; and, as the former does not depend on the material employed (excepting iron) it was important to use substances of high specific resistance. Carbon or platinoid being available, the latter was chosen on account of its low temperature coefficient. One form of resistance exhibited consisted of strips of thin sheet platinoid about 6 metres long and 4 centimetres wide. Each was bent at the middle and doubled back on itself, thin silk being placed between the contiguous parts and narrow ribbon used to bind the parts together. Twelve such strips arranged in series had a resistance of $2 * 95 \mathrm{ohms}$, and would carry a current of 15 amperes without changing its resistance more than ${ }^{\frac{1}{10}}$ per cent. This strip-resistance was made by Messrs. C. G. Lamb and E. W. Smith, who at that time (1888) were students in the Central Institution, and to whom the author's best thanks are due for the praiseworthy manner in which they surmounted the difficulties which presented themselves. Another form of resistance designed for portability consisted of bare-wire spirals, each length having a left-handed spiral placed within a right-handed one of slightly larger diameter, and the two being connected in parallel. This device was found to reduce the inductance to $\frac{1}{10}$ or $\frac{1}{20}$ of that of a single spiral according as the diameters of the spirals approach towards equality. Where the spirals are made of platinoid wire, the ratio of inductance to resistance is very small, averaging about $\frac{1}{5 \pi 0} \div 0 .-$ - On the influence of surface loading on the flexure of beams, by Prof. C. A. Carus-Wilson. Referring to the practical treatmint of problems on beam flexure as based on Bernoulli's hypothesis that the bending moment is proportional to the curvature, the author pointed out that this assumes that the cross-sections remain plane after flexure, and neglects the surface loading effect. The present paper describes experiments made to determine the actual state of strain in a beam doubly supported, and carrying a single load at the centre, the effect of surface loading being taken into account. The method of investigation assumes that (I) the true state of strain at the centre of a beam may be found by superposing on the state of strain due to bending only, that due to surface loading without bending; (2) the state of strain due to surface loading only, may be found with close approximation to truth by resting the beam on a flat plane instead of on two supports (3) the strain due to bending alone, may be obtained from the Bernoulli-Saint-Venant results. Before proceeding to describe the experiments, a short account of the mathematical work previously done on the subject was given. The nearest approach to the particular case here dealt with had been worked out by Prof. Boussinesq, who had shown that for an infinite elastic solid bounded on one side by a plane surface and loaded along a line on that surface, the stress $(y)$ on an element on the normal through the middle point of the line varies inversely as its dis-

$$
\text { NO. I I } 33 \text {, VOL. 44] }
$$


tance $(x)$ from the surface. The formula thus arrived at was $y=0.64 \frac{P}{x}$, whilst for a finite beam centrally loaded the author's experiments gave $y=0.726 \frac{\mathrm{P}}{x}$. The experiments were made on glass beams mounted in a steel straining frame, and placed between the crossed Nicols of a polariscope. Steel rollers $2 \mathrm{~mm}$. in diameter served as supports, and the central load was applied by a screw acting on a roller of similar diameter. Deflections of the beam were measured by a micrometer screw at a point opposite the central load, and traversing screws enabled the whole frame to be moved so as to bring any portion of the beam in the field of view. Circularly polarized light was sometimes used, and a micrometer eye-piece served to measure the distances between interference fringes produced by loading. By carefully chosen experiments the author had shown that if a beam of glass be laid on a flat surface and loaded across its upper surface, the shear at any point on the normal at the point of contact of the load is inversely proportional to the distance from the point of contact. In the first experiment the crossed Nicols were set at $45^{\circ}$ to the axis of the loaded bar ; a quarterwave plate was then placed between the bar and the analyzer, and the position of the black spot at the point where the effect of the shear on the polarized light was equal and opposite to that produced by the quarter-wave plate was noted. A second quarterwave plate was then superposed on the first; the black spot moved upwards to a point where the shear was double that at the first position. This position having been determined; one quarter-wave plate was removed, and the load diminished until the original spot moved up to the second position, and the processes repeated. By this means a series of positions at which the shears were in the proportions I, 2, 4, 8, \&c., were determined. Plotting the results showed the curve connecting the shear and the distance from the point of contact to be hyperbolic. Othcr experiments showed that the shear at any point was proportional to the load. By maintaining a constant load and measuring the distances between the interference fringes below the point of contact the hyperbolic law was confirmed. The effect of bending a beam is, according to hypothesis, to put the upper portion in longitudinal compression, and the shear (vertical stretch) varies as the distance from the centre of the beam; the shear due to surface loading is a vertical squeeze, and, as shown above, varies hyperbolically. When, therefore, the beam is subjected to both actions, the straight line representing the bending strain may intersect the hyperbola representing the shear due to surface loading in two points, and since, at the corresponding points in the central section, the shears are equal and opposite, the elements are only subjected to voluminal compression, and will exert no bi-refringent action. Hence, wher viewed through crossed Nicols, black spots will be seen on a white field. Keeping the load constant and diminishing the span should cause the spots to approach each other, and when the line is tangential to the hyperbola, the spots coincide. These deductions were confirmed by experiment, and it was found that for a span of less than four depths, no point of zero shear exists on the central section. The strains in beams subjected to surface loading were thus shown to be of a character different from those usually assumed, the neutral axis instead of coinciding with the axis of the beam, being lifted up in the centre, and its shape depending on the load and span. Other ingenious and interesting experiments on beams were described, in some of which the lines of principal stress were mapped out. Remarkable results were obtained, showing that although the tension lines given by Rankine and Airy are nearly correct, the curves of compression may be very different, and have very curious shapes. Prof. Perry thought the local loading effect would not be so important in long beams, and inquired whether in ordinary test pieces local loading would affect the breaking strength. He also asked what effect the fact of the load making contact over a surface instead of along a line would have on the results, and in reply Prof. Carus-Wilson said the effect was to raise the asymptote of the hyperbola representing the surface loading stress above the surface of the beam. - On pocket electrometers, by C. V. Boys, F.R.S. This communication described modifications of electrometers adapted for portability. As quartz fibres increase the deiicacy and diminish the disturbing influences affecting instruments, much smaller controlling forces can be employed than when silk is used for suspensions. $\mathrm{He}$ had, he said, pointed out some time ago the great advantages arising from making galvanometers small. Applying similar reasoning to electrometers, he remarked that making an instrument one-tenth the size of an existing one reduced the moment of inertia of the needle to $\frac{\mathrm{I}}{\mathrm{IO}^{5}}$, whilst the deflecting couple for given potentials would only be $\frac{1}{10}$ of its former value. The small instrument would for the same periodic time be Io, 000 times more sensitive than the large one, provided the disturbing influence could be reduced in the same proportion. This, however, was not ordinarily possible, for any method of making contact with the needle, such as by a fine wire dipping into acid or mercury, prevented very small controlling forces being used. Still, by suitable devices a large proportion of the full advantage could be obtained; a freely suspended needle without liquid contacts was essential to success. The first instrument described was one in which the needle was cylindrical, contiguous quarters being insulated and connected to the opposite ends of a minute dry pile placed within the needle; opposite quarters were thus at the same potential, and at a different potential to the other pair of quarter cylinders. This was suspended within a glass tube silvered on the inside and divided into four parts by fine longitudinal lines. In such an instrument the needle and quadrants are reciprocal, and the deflection depends on the product of the difference of potential between the quadrants and that between the parts of the needle. Owing to the dry pile not being constant, the instrument was found untrustworthy, but when working at its best a Grove cell would give 30 or 40 millimetres deflection. The next step was to make a cross-shaped needle of zinc and platinum, and rely on contact electricity to keep the parts of the needle at different potentials. This bold experiment proved remarkably successful, for the instrument was very sensitive. A disk-shaped needle with quadrants, alternately zinc and platinum, was then employed, and by this a small fraction of a volt could be measured. The weight of the disk was only $\frac{1}{2} 0$ of a gramme, and the instrument could be turned upside down or carried about in the pocket with impunity. Another small instrument with the stationary quadrants of zinc and copper was exhibited, and by rotating them through an angle of $90^{\circ}$, so as to bring them in a different position relative to the parts of the needle, a deflection of several degrees of arc was produced. In the course of his remarks Mr. Boys made several suggestions relating to ballistic electrometers and electrostatic Siemens dynanometers, and pointed out the possibility of instruments such as he had exhibited being of use in elucidating the obscure points in connection with so-called " contact electricity." The President complimented Mr. Boys on the beautifully simple and remarkably sensitive electrometers exhibited. He remembered that some years ago $\mathrm{Mr}$. Gordon made a very small electrometer, but its insulation was insufficient for electrostatic work. He agreed with Mr. Boys as to the advantages of small instruments, providing sparking across or tilting of the needle could be prevented. On the other hand, he thought the use of small potential differences on the needle was a step in the wrong direction, when great sensibility was required. Prof. Perry asked if the needle could not be kept charged by occasional contacts with a charged acid cup. Mr. Boys said he had originally intended using a fairly highly charged needle, but had not yet done so. He also suggested that an electrometer of very small capacity might be made by reducing the quadrants surrounding a disk-needle, until they became like small tuningforks. - A paper on electrification due to the contact of gases with liquids, by Mr. J. Enright, and one on the expansion of chlorine by heat, by Dr. Arthur Richardson, were taken as read.

Entomological Society, July I.-Mr. Frederick DuCaneGodman, F.R.S., President, in the chair.-Mr. Jacoby exhibited a specimen of a species of Coleoptera belonging to the family Galerucido, with the maxillary palpi extraordinarily developed. -Canon Fowler, on behalf of $\mathrm{Mr}$. Wroughton, Conservator of Forests, Poona, exhibited specimens of a bug imitating an ant, Polyrachis spiniger, and of a spider imitating a species of Mutilla, and read the following notes:- "I have taken a good many specimens of a bug which has achieved a very fair imitation of Polyrachis spiniger (under the same stone with which it may be found), even to the extent of evolving a pedicle and spines in what, were it an ant, would be its metanotum. Curiously enough, however, these spines are apparently not alike in any two specimens. Is it that this bug is still waiting for one of its race to accidentally sport spines more like those of

NO. I I 33, VOL. 44] 
$P$. spiniger, and thus to set the ball of evolution rolling afresh ? or is it that the present rough copy of spiniger's spines is found sufficient to deceive? The bug has also been found in the Nilgherries. Mr. Rothney remarks on the above species :- 'I have not found the species mimicking Mutilla; but in Calcutta and Barrackpore, where $P$. spiniger is a tree ant, forming its net by spinning together the twigs of a shrub, the mimicking bug also assumes arboreal habits, and may be found on the trunks of trees with the ants." "-Mr. Porritt exhibited living specimens of Eupithecia extensaria and Geometra smaragdaria: the position assumed by the former proved conclusively that it had rightly been placed in the genus Eupithecia.-Mr. Crowley exhibited two specimens of a Papilio from the Khasia Hills, belonging to an undescribed species allied to $P$. papone, subgeneric section Chilades. Colonel Swinhoe remarked that he possessed a specimen from Northern Burmah. Mr. Moore and others took part in the discussion which followed.-Mr. Dallas Beeching exhibited a specimen of Plusia moneta, recently taken by himself at High Woods, Tonbridge, and specimens of Goneptery $x$ cleopatra, lent him for exhibition, which were alleged to have come from the same locality.-Dr. Algernon Chapman exhibited the larva of Micropteryx calthella, and read notes on hem.-Colonel Swinhoe read a paper entitled "On New Species of Heterocera from the Khasia Hills."-Mr. Crowley read a paper entitled "On a New Species of Prothoe."-Mr. C. J. Gahan read a paper entitled "On the South American species of Diabrotica, Part 2," being a continuation of Dr. Baly's paper on the same genus published in the Society's Transactions for I890, Part I.--Mr. W. F. Kirby communicated a paper entitled "Notes on the Orthopterous family Mecopodida."-Prof. Westwood communicated a paper entitled "Notes on Siphonophora arlocarpi."

\section{EDINBURGH.}

Royal Society, June I5--Mr. T. B. Sprague in the chair.Dr. Johnson Symington and Dr. H. A. Thomson communicated a paper on a case of defective endochondral ossification in a human fœtus.-Dr. J. Berry Haycraft read a paper on the alkaline and acid salts of the blood and urine, and especially those of phosphoric acid.-Dr. J. M. Macfarlane presented the second part of a paper on the structure, division, and history of vegetable and animal cells, in which he stated that as a result of extended observation he still adhered to the view that a typical cell consists of protoplasm, nucleus, nucleolus, and endonucleolus, the whole usually surrounded by a cell wall; that the nucleolus is the important part equally in division and in sexual union of cells; that after division had ceased, successive fragmentation of endonucleolus, nucleolus, and nucleus occurred, though to a varying degree in different cells; that thus a multiendonucleolar was followed by a multinucleolar, and this by a multinuclear state. He regarded the nucleolus of every cell as the sexual centre directly derived from union of the chromatic substance of the male and female pronuclei of the ovum, and that from the nucleolus extremely fine radiating threads of chromatic substance passed out along the achromatic fibrils, which last he viewed as a finely differentiated reticulum of the ground protoplasm. By union of the radiating chromatic threads, the author considered that the nuclear membrane was formed, while continuations radiated outwards from this through the cell-protoplasm to convey stimuli to and from the sex-centre or nucleolus. He further stated that many facts and direct observations made tended to show that the radiating threads from the nucleus, and ultimately therefore from the nucleolus, of one cell are connected with corresponding ones from other cells, and this, if fully verified, would cause us to regard an organism as a sexual whole, and the male and female reproductive cells as being specially set aside to hand down hereditary and acquired conditions. He showed that this had a special bearing on the next communication submitted-a comparison of the minute structure of plant hybrids with that of their parents, and its bearing on biological problems. At a previous meeting of the Society (May 4) he directly demonstrated, by three parallel lantern exhibitions of micro-photographs, that the tissues of root, stem, leaf, and flower parts in the hybrid named by Dr. Masters Philageria Veitchii, are exactly intermediate, when of corresponding age, between those of the parents ; and further, that when a structure is developed in one parent, but is absent in the other-e.g. the sepal honey gland of Lapageria-the hybrid shows it of half the size. He now referred to eleven other hybrids whose tissues he had worked over in detail, and selected points from about sixty others, NO. I I 33 , VOL. 44] examined more or less minutely. By triplets of micro-photographs the author not only demonstrated that a hybrid is, to its minutest details, a blended reproduction of both parents, but that where the parents show diverse morphological details, these may be handed down to the hybrid of half the size, or one only may be inherited. He advanced a theory to explain this, and then compared the tissues of Cytisus Adami (see also Gard. Chron., July I890, p. 94), which he regarded as a true graft hybrid. He concluded by referring to the colour, flowering period, and constitutional vigour of plant hybrids, and to the light shed by these inquiries on the effects of environment, on the influence of sex, and on heredity.-Prof. Tait communicated paper, by Prof. Stokes, on an optical proof of the existence of suspended matter in flames. The method consists in condensing sunlight on the flame. The light is scattered by the solid particles in an extremely thin layer both where the beam enters the flame and where it leaves it. It is polarized in the plane of reflection. The effect is not found in some flamessuch as a Bunsen flame tinged with burning sodium. In the latter case this seems to be due to the fact that the sodium is in the form of vapour-not of solid particles.

\section{Sydney。}

Royal Society of New South Wales, May 6.-Annua Meeting.-Dr. A. Leibius, President, in the chair.-The Report stated that 25 new members had been elected during the year, and the total number on the roll on April 30 was 457. During the year the Society held eight meetings, at which the following papers were read:- Presidential address, by Prof. Liversidge, F.R.S.-On a compressed-air flying machine, by L. Hargrave. - On the treatment of slips on the Illawarra Railway at Stanwell Park, by W. Shellshear.-On native names of some of the runs, \&c., in the Lachlan district, by F. B. W. Woolrych.-Remarks on a new plant rich in tannin, by Charles Moore.-Record of hitherto undescribed plants from Arnheim's Land, by Baron Ferd. von Mueller, F.R.S. - The theory of the repetition of angular measures with theodolites, by G. H. Knibbs. - On some photographs of the Milky Way recently taken at Sydney Observatory, by H. C. Russell, F.R.S.-Australian aborigines : varieties of food and methods of obtaining it, by W. T. Wyndham. -On the application of the results of testing Australian timbers to the design and construction of timber structures, by Prof. Warren.-Geological notes on the Barrier Ranges silver-field, by C. W. Marsh.-Some folk-songs and myths from Samoa, by the Rev. T. Powell and Rev. G. Pratt, with an introduction and notes by Dr. John Fraser. - The coal-fields of New South Wales and their associated eruptive rocks, by T. W. E. David. - Some remarks on the Australian languages, by Dr. John Fraser.-On the 74-ounce compressed-air flying machine, by L. Hargrave. - The Medical Section held seven meetings, at which nine papers were read; the Microscopical Section held seven meetings, at which interesting exhibits were shown. - The Clarke Medal for the year 1891 had been awarded to Prof. F. W. Hutton, Canterbury College, Christ Church, New Zealand. - The Council had issued the following list of subjects with the offer of the Society's bronze medal and a prize of $£ 25$ for each of the best researches if of sufficient merit :- (To be sent in not later than May I, I892) Oa the iron-ore deposits of New South Wales; on the effect which settlement in Australia has produced upon indigenous vegetation, especially the depasturing of sheep and cattle ; on the coals and coal measures of Australasia. (To be sent in not later than May I, 1893) Upon the weapons, utensils, and manufactures of the aborigines of Australia and Tasmania; on the effect of the Australian climate upon the physical development of the Australian-born population; on the injuries occasioned by insect pests upon introduced trees. - A most successful conversazione had been held in the Great Hall of the University on December 10, at which 800 guests were present. -The Chairman read the Presidential Address, and the officers and Council were elected for the ensuing year, Mr. H. C. Russell, F.R.S., Government Astronomer, being President.

\section{PARIS.}

Academy of Sciences, July 6.-M. Duchartre in the chair. - On the lunar inequality of long period due to the action of Venus, and depending upon the argument $l+\mathrm{I} 6 l^{\prime}-8 l^{\prime \prime}$, by M. F. Tisserand. According to Delaunay, in calculations of this inequality it is possible to neglect powers of the inclination of the orbit of Venus higher than the second. M. Tisserand shows, however, that terms which contain the fourth power of the 
inclination may have a sensible influence, and diminish the coefficient of the inequality in question by a tenth of its valuethat is, by about $\mathbf{x}^{\prime \prime} \cdot 6$. - On the manner in which the velocities are distributed from the entrance of a cylindrical tube of circular section widened at the mouth up to the points where uniformity is established, by M. J. Boussinesq. - The flight of insects studied by photochronography, by M. Marey. The author describes an apparatus which he has used to obtain photograph of flying insects. It allows exposures to be made so short. as 1 of a second. His observations indicate that the wings of insects in flight, by meeting obliquely the resistance of the air in to-and-fro movements, act in a very similar manner to the sculls used to propel rowing-boats. - Study of the tetra-iodide of carbon, by M. Henri Moissan. By acting on carbon tetrachloride with boron tri-iodide, the trichloride of boron and the tetra-iodide of carbon are obtained by double decomposition. A detailed account is given of this reaction. The carbon tetraiodide thus prepared forms comparatively large crystals of a beautiful red colour, very similar to the rubies synthetically prepared by MM. Fremy and Verneuil. Several new reactions with this compound are described.-Compounds of camphors with the aldehydes: on a new mode of formation of alkyl camphors, by M. A. Haller.-The Eocene formations of Algeria, by MM. Pomel and Ficheur. It has been previously shown that the Eocene formations of Algeria may be divided into the three groups, lower, middle, and upper. The observations now stated indicate that the Middle Eocene formations only extend over a narrow zone, and that they are characterized by Nummulites of the groups Numm. lavioata and Numm. perforata. The Lower Eocenes are defined from a nummulitic point of view by Numm. planulata, Numm. biarritzensis, and Numm. gizehensis. - Method of ready transformation of the tubercular products of joints and certain other parts of the human body, by M. Lannelongue.-On the determination of the constants and coefficients of elasticity of nickel-steel, by $\mathrm{M}$. E. Mercadier. Experiments have been made to determine the relation $\frac{\lambda}{\mu}$ for solid sonorous bodies, and, therefore, the coefficient of dynamical elasticity, by a method founded on Kirchhoff's theory of vibration of circular disks. From the results obtained it appears that the incorporation of a sufficient quantity of nickel with steel tends to make the alloy isotropic. The mean coefficient of dynamical elasticity for alloys containing about 5 per cent. and 25 per cent. of nickel is 18,600 , whereas that of pure steel is 20,700 . - Calculation of molecular volume, by $M$. G. Hinrichs.-On an explosive compound which results from the action of baryta water on chromic acid in the presence of oxygenated water, by M. E. Péchard. By adding baryta water in the presence of an excess of oxygenated water, a precipitate is produced, which, after desiccation, explodes violently by heat or percussion. The compound has the formula $\mathrm{BaO}_{2}$. $\mathrm{CrO}_{3}$.On the detection of small quantities of boric acid, by M. F. Parmentier.-On the structure of the ocellates of Lithobius forficatus, by M. Victor Willem.-Comparative study of the development and morphology of the parapodia of Syllidiæ, by M. A. Malaquin.

\section{Göttingen.}

Royal Society of Sciences.-The Proceedings of the Society for February, March, and May 1891 contain the following papers of scientific interest :-

No. I.-W. Nernst : on Henry's law of chemical equilibrium in solutions.-F. Meyer : on discriminants and resultants of singularity-equations. - O. Venske : contribution to the integration of the equation $\Delta^{2} u=0$ for certain plane figures (the disk, the annulus, the rectilineal angle, the rectilinear strip with parallel sides, the annular sector).

No. 2.-W. Voigt : contributions to hydrodynamics (pulsating sphere or cylinder in an infinite liquid; stationary waves in a stream as an example of Kirchhoff's theory of liquid stream-rays ; successive approximation to the irrotational motion of a heavy liquid with free surface ; stationary combined motions depending on two co-ordinates in a liquid under a conservative system of forces; non-stationary current-motion, partly rotational, partly irrolational, within an ellipsoidal shell at rest).-O. Venske : integration of a special system of linear homogeneous differential equations, with doubly periodic functions as coefficients. $-F$. Meyer : on real properties of curves in space.

No. 3.-G. Tammann : on conduction through membranelike precipitates.-O. Venske : a new apparatus for the deter- mination in absolute measure of the internal thermal conductivity of badly conducting bodies.

\section{STOCKHOLM.}

Royal Academy of Sciences, June I0.-On the treatment of cancer through injections, by Prof. Rossander.-Analysis of a pyrite, which seems to contain a new element, by Herr L. J. Igelström.-A letter from Baron Ferd. von Mueller on the Australian contributions towards a South Polar expedition planned in Sweden, communicated by Baron Nordenskiöld. - The intensity of the radiation of gasenus bodies under the influence of an electric discharge, by Dr. K. Ångström. - On derivates of sulphur urates, iii., by Dr. Hector.-A solution of a mechanical problem which leads to the functions of Rosenhain, by Dr. Olsson.Some experiments on the respiration of the Algæ, by Miss $\mathrm{H}$. Lovén. - The African genera of the Calandrides related to the Oxypisthens, by Prof. Chr. Aurivillius.-A comparison between the methods of Angström and Neumann for determining the conductibility of heat in bodies, Part iii., by Dr. Hagström. - On I-6 dibrom-naphthaline, by Herr Forsling.-Triazol combinations produced from aldehydes and dicyan-phenyl-hydrazine, by Herr Holmqvist. - On the ammoniacal combinations of iridium, by Dr. Palmær. - On the formulas for calculating the mortality during the first year of human life, as derived from the statistics of the population, by Dr. G. Eneström.

\section{BOOKS, PAMPHLETS, and SERIALS RECEIVED.}

Among the Butterflies: B. G. Johns (Isbister).-The Business of TraveI W. F. Rae (Cook). -The Melanesians: Dr. R. H. Codrington (Clarendon Press).-Verlags-Catalog von R. Friedländer und Sohn, x830-9o (Berlin, Friedländer). - The Geology of Nova Scotia, \&c., or Acadian Geology, 4th edition: Sir J. W. Dawson (Macmillan and Co.).-British Cage Birds, Part I5: R. L. Wallace (U. Gill).-North Midland School Cookery Book (Raithby),-Der Peloponnes Versuch einer Landeskunde auf Geologischer Grundlage, Abtg. I: Dr. A. Philoppson (Berlin, Friedländer). Darkness and Light in the Land of Egypt: Colonel Fraser (Sutton). -Die organischen Elemente und ihre Stellung im System: W. Preyer (Wiesbaden, Bergmann).-Destructive Locusts : C. V. Riley (Washington).-U.S. Department of Agriculture-Reports of Observations and Experiments (Washington).--Insect Life, vol. iii., Nos. 9 and ro (Washington). Stonyhurst College Observatory-Results of Meteorological and Mag netical Observations, x889-90: Rev. W. Sidgreaves (Market Weighton) -Simple Recipes for Sick-Room Cookery: Mrs. Buck (Raithby).-Journa of the Royal Agricultural Society, vol. ii. Part ii. No. 6 (Murray).-Journal of the College of Science, Imperial University of Japan, vol. iv. Part (Tokio).-Mind, July (Williams and Norgate). - The Pedagogical Seminary, vol. i. No. 2 (Worcester, Mass.). - The Econonic Journal, No. 2 (Macmillan and Co.).-London and Middlesex Note-Book, No. 2 (E. Stock).

\section{CONTENTS.}

Organizers of Technical Education in Conference.

(With Map)

The Evolution of Animals. By R. Lydekker . 24

Metallurgy. By Prof. W. C. Roberts-Austen, F.R.S. 245

Bacteria and their Products . . . . . . . . . 246

Our Book Shelf:-

Gordon: "Our Country's Flowers."-C. H. W.

Pascoe: "A Summary of the Darwinian Theory of the Origin of Species."-R. M. . . . . . 247

Rae : "The Business of Travel" . . . . . . . 247

Letters to the Editor:-

The Albert University.-Prof. G. Croom Robertson; Rev. A Irving

Name for Resonance.-Prof. 'oliver J.' Lodge, F.R.S.

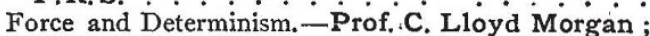
Edward T. Dixon.

Magnetic Anomalies. -Affonso Sella . . . . . . . . . 249

Physical Religion. -B. Woodd Smith . . 249

Some Applications of Photography. (Illiustrated.)

By Lord Rayleigh, F.R.S. . . . . . . . . 249

The Smithsonian Astro-physical Observatory . . . 254

The New Gallery of British Art . . . . . . . 255

Cardinal Haynald . . . . . . . . . . 256

Oxford Summer Meeting of University Extension

Students . . . . . . . . . . . 256

The Proposed Teaching University for London . . 257

Notes ............. 257

Our Astronomical Column:-

The Stellar Cluster $\chi$ Persei . . . . . . . 259

On the Vegetation of Tibet ........ 260

Societies and Academies . . . . 260

Books, Pamphlets, and Serials Received . . . 264

NO. I I 33, VOL. 44] 